\title{
CANCER AND THE RADIOTHERAPIST
}

\author{
A. M. Jelliffe, M.D., M.R.C.P., F.F.R. \\ Consultant Radiotherapist, The Middlesex Hospital, W.I, and Mount Vernon Hospital, Northwood
}

THE first cure of skin cancer with ionizing irradiation was reported in 1899 . Within a few years the new rays had been tried out on many disease processes, including deep tumours. Cures of superficial, accessible cancers were reported in increasing numbers, but at the same time complications followed the use of the new rays. These included the production of cancer. By the r930s radium and radon were established firmly in the radiotherapist's armamentarium and so-called deep 200- to 250-kilovolt X-rays were in general use for the external treatment of cancer. Experiences with a few small 'ro-g. radium 'bomb' units and one or two higher voltage $\mathrm{X}$-ray machines indicated that better results might be obtainable with external irradiation using harder, more penetrating rays.

It has recently become practical clinically to produce supervoltage X-rays from cyclical or linear accelerators, and an additional impetus has been given to radiotherapy by the availability of ${ }^{60}$ Co sources, emitting a gamma-ray beam equivalent to X-rays from a machine of between 2 and 3 million volts. Other techniques that have been investigated enthusiastically over the last few years include rotation therapy, charged particle irradiation, isotopic replacements for radium and radon, and the chemical or biological modification of the radiation response.

Probably the most encouraging recent tendency has been the increasing co-operation between the radiotherapist and all other branches of medicine. Combined clinics are becoming accepted features of medical practice, with considerable benefit to the patient. Only in this way will radiotherapists continue to improve their results.

\section{Megavoltage Therapy}

X-ray machines of I million volts or more and megacurie isotope units can be referred to collectively as megavoltage units. The ionizing irradiation from this type of machine possesses several advantages over that from the old 200- to $250-\mathrm{kV}$. $\mathrm{X}$-ray therapy machine. The greatest effect from an incident beam on the skin occurs below, and not on, the surface, and patients are therefore spared unpleasant skin reactions. There is also a reduction in the frequency and intensity of radiation sickness. The radiotherapist finds his task simplified by the greatly increased depth dose which enables him to give any required dose to any region of the body. There is relatively less energy absorption in bone, and post-irradiation necrosis and fracture should occur much less commonly. These are very considerable advantages.

For example, when treating a patient with bronchial carcinoma the limiting factor used to be the skin reaction. The most common side-effect with megavoltage therapy is an œsophagitis before any skin reaction develops. Attempts can therefore be made to attack energetically many deep-seated tumours and palliation can be achieved with much less disturbance of the patient. Radiotherapists who have once worked with megavoltage units find that it is impossible to do the best work without their help.

The comparative cost of obtaining and maintaining supervoltage X-ray machines and megacurie radiocobalt units must be considered. Radiocobalt units are cheaper in both respects, but the output of present-day units is slow when compared with that of supervoltage $\mathrm{X}$-ray machines. The output will improve when new high-intensity ${ }^{60} \mathrm{Co}$ sources become generally available. The main advantage of the 8- to $30-\mathrm{MV}$. X-ray machine will then lie in the possibility of using not the X-rays, but the electron beam. (See below, 'Charged Particle Irradiation'.)

It must be remembered that there is little or no difference in the biological effects of megavoltage radiation and conventional $250-\mathrm{kV}$. X-rays, apart from the need to give about $15 \%$ more at the higher energy levels, to achieve the same tissue effects (Patterson, 1960). It is therefore unlikely that many more cancers will become curable, although more deep-seated tumours should now be treatable, including cancers of the lung, œsophagus, large bowel, bladder and other abdominal and pelvic tumours. Unfortunately, many of these cancers metastasize rapidly and it is this which so often decides the patient's fate. 
Many so-called ' radio-resistant' tumours can now be treated adequately. The subject was discussed in detail by Flatman (1959). The need for a large dose of irradiation will increase the risk of complications developing and, when possible, surgery is always the preferred form of treatment. With inoperable cancers the possibility of radiotherapy should be considered carefully and not rejected because the tumour is known to be of a relatively radio-resistant type. So-called ' radioresistant' tumours which may respond to treatment include malignant melanoma, fibrosarcoma, chondrosarcoma, osteosarcoma, and some adenocarcinomas of the alimentary tract.

\section{Rotation Therapy}

The logical extension of multiple entry ports is to rotate the beam of radiation over the patient during treatment while directing it constantly on the tumour. In this way the maximum skin sparing is possible and a high dose can be delivered to deep-seated tumours.

This is not a new idea, having been suggested originally in 1906 (Nielsen and Jensen). Although extremely useful and convenient in some situations, now that megavoltage therapy is available it is never a necessity. The subject was discussed recently in detail at the British Institute of Radiology and various aspects will be published shortly (Jelliffe, 196r). The two principal methods are either to rotate the patient on a chair or couch in a fixed beam, or to move the radiation source over the horizontal patient. The second method is practical with a megacurie ${ }^{60} \mathrm{Co}$ source, when the patient 'set-up' is particularly easy. An ingenious extension of rotation is the use of tracking, which allows the irradiated volume to follow the anatomical spread of the disease (Green, 1959). With superficial tumours dose calculation becomes less accurate and it is more logical to rely upon fixed fields, often with wedge filters. Smithers (1954) published an excellent account of rotation therapy.

\section{Charged Particle Irradiation}

$\mathrm{X}$-rays or gamma-rays interact in tissues to produce electrons which are ejected for varying distances, depending upon the energy of the incident beam. It is these electrons which are ultimately responsible for the biological effects of irradiation. X-ray beams are attenuated exponentially.

There is one great advantage if treatment is carried out with beams of accelerated charged particles. The final biological effect is the same, but the range of the particles is finite, depending upon their initial energy and mass, and the density of the tissues in which they are absorbed. It is therefore possible to limit the effects of the irradiation strictly to the desired depth and completely avoid deeper structures.

Charged particle irradiation can be divided into three main therapeutic groups. Beta-rays, which are usually negatively-charged 'electrons', are emitted from most radio-active isotopes, as a rule in combination with gamma-rays or alphaparticles. Pure beta-ray emitters include ${ }^{32} \mathrm{P},{ }^{90} \mathrm{Sr}$ and ${ }^{144} \mathrm{Ce}$. The $50 \%$ range of beta-rays from these isotopes in normal tissues is about $\mathbf{I ~} \mathrm{mm}$. and it is therefore possible to treat extremely superficial structures. The isotope can be enclosed in a suitable metal applicator for treating small areas of skin. Haybittle has described a I0-c. ${ }^{90} \mathrm{Sr}$ unit which can be used in combination with a moving couch to give whole body beta-ray irradiation (Horwitz and Haybittle, 1960).

More penetrating beta-particles can be obtained from linear and cyclical accelerators in the 8 to $30 \mathrm{MV}$. range. These machines produce $\mathrm{X}$-rays by the impaction of a fast-moving stream of electrons on a metal target. By replacing the metal target by a more radiotranslucent window or by deflecting the beam of electrons, it is possible to make use of the actual particle beam for therapy. Morrison has recorded his clinical experiences with a beam of up to 8-MV. electrons (Batchelor, Bewley, Morrison and Stevenson, 1959). Several centimetres of tissue can be uniformly treated in this way. Other workers have reported the use of a combination of high energy $\mathrm{X}$-rays and electrons for the treatment of patients (Gale and Innes, 1960).

In one or two centres cyclical accelerators 'are available which are capable of producing beams of charged particles at extremely high energies. Lawrence and Tobias (1956) have reported their experiences with the 184 -in. synchro-cyclotron at Berkeley, California. Using I90 MV. deuterons and protons in a carefully collimated beam, they have successfully destroyed the pituitary of patients with advanced breast cancer. It is quite clearly impractical for this type of machine to be used in more than a few centres, but there seems to be a real need for the medium range type of electron therapy. It could completely replace the superficial use of radium and radioactive isotopes in the form of applicators, with all their attendant dangers to the wearer and to the medical staff. It is to be hoped that linear accelerators or betatrons in the 8 to $30 \mathrm{MV}$. range will be available eventually in all large radiotherapy centres.

\section{The Modification of the Effects of Irradiation}

Ionizing radiations destroy cancer because of their selective action upon the dividing cell. With megavoltage equipment it has become possible to 
deliver any desired dose to any part of the body. Further improvements in the results of routine treatment with radiotherapy are most likely to occur if it becomes possible either to increase the relative sensitivity of the cancer cell to ionizing radiations by chemical or biological methods, or to protect the normal tissues against their damaging effects.

Bone Marrow Replacement. Bone marrow cells are extremely sensitive to ionizing radiations and the blood count has been recognized as one of the most important limiting factors in large-volume radiotherapy. Recently a great deal of work has been carried out on the replacement of autogenous marrow, stored during radiotherapy at $-79^{\circ} \mathrm{C}$., and also of foreign adult and fœtal hæmopoietic tissue (Kurnick, Montano, Gerdes and Feder, 1958; Newton, 1960; Humble, 1960; Pegg and Kemp, 1960). Lajtha (1960) is extremely doubtful if replacement with stored autologous marrow has any therapeutic value and there are many immunological difficulties to be overcome when foreign marrow is used (Porter, 1960). One case of longterm survival of a foreign marrow transplant without the development of secondary disease has been recorded (Bielby, Cade, Jelliffe, Parkin and Stewart, 1960). Bone marrow replacement may prove to be of great value in radiotherapy, but much work remains to be done before it can be accepted as a useful routine procedure.

The Oxygen Effect. The damaging effects of ionizing radiation can be markedly reduced by the absence of oxygen. Anoxia offers a considerable degree of protection and large tumour masses are often avascular and anoxic at the centre. As the oxygen tension is raised, so the sensitivity increases, reaching a maximum at the oxygen tension found under normal physiological conditions. Raising the oxygen tension above the normal level is therefore unlikely to increase the sensitivity of normal tissues, but there will be a greater chance of oxygen diffusing into the centre of avascular cell masses, with a greater response to irradiation (Gray, Conger, Ebert, Hornsey and Scott, I953).

The problem has been investigated clinically by Churchill-Davidson and his colleagues (ChurchillDavidson, Sanger and Thomlinson, 1957). These workers have used oxygen pressures of up to 4 atm. Patients have been anæsthetized and bilateral myringotomies carried out to prevent the development of complications. More recently Emery (1960) has described an apparatus in which unanæsthetized patients have been irradiated at raised oxygen tensions without the development of complications. There appears to be increased tumour sensitivity under these conditions, but no large statistically-controlled series has been published to date.
Clearly anoxia could also be used in an attempt to decrease the sensitivity of normal tissues during routine radiotherapy. This interesting possibility has not been explored adequately at the clinical level.

Chemical Potentiation. Spasmodic attempts at increasing the radiosensitivity of tumours with chemical substances have been made since the earliest days of radiotherapy. The extremely variable natural history of cancer makes it essential to have a statistically-controlled series of patients and all the early work is quite valueless.

Synkavit. Mitchell (1953) has carried out careful clinical studies of the radiosensitization effects of Synkavit and a number of closely related compounds. His results suggest a small but often useful improvement in the results of the radiotherapy of bronchial carcinoma. This work is of the highest quality and is an excellent model upon which future experiments of this type can be based. A review of this work and also of other possible radiosensitizers has been published recently (Mitchell, 1960).

Alkylating Agents. Nitrogen mustard derivatives and other alkylating agents are sometimes used in combination with radiotherapy, partly with the object of obtaining an additive tumouricidal effect and partly because it is thought by some that these agents increase radiosensitivity. One of the few publications on the subject suggests that there is no statistical evidence of an improved cancericidal effect from such a combination (Lochman and Morris, 1956).

Other Agents. These include porphyrins, alpha-tocopherols, æsculin, urethane derivatives, colchicine derivatives, iodoacetic acid, dinitrophenols, megaphen and actinomycin D. They are referred to in detail in the reviews referred to above and by Patt (1958) and Bane and co-workers (Bane, Conrad and Tarnowski, 1957). On the whole insufficient controlled work has been carried out to allow the publication of statistically significant results.

Chemical Protectors. No chemical protecting agent has yet been generally accepted as a routine measure in radiotherapy. The best authenticated protector against the effects of whole body irradiation is cysteine (Bacq and Alexander, 1955). There is some evidence that large doses of cortisone or its derivatives protect against the local inflammatory effects of radiation, particularly in the lung (Moss, Haddy and Sweany, r960).

\section{Radioactive Isotopes}

The therapeutic application of artificially produced radioactive isotopes began before 1939 . 
Since 1945 almost every known isotope has been considered for clinical purposes. The majority have been rejected, but a few have established themselves and are valuable members of the radiotherapist's armamentarium.

\section{Radium and Radon Substitutes}

Cobalt 60 is an excellent radium substitute. It emits a hard gamma-ray, equivalent to that from a 2 to 3 million-volt supervoltage X-ray machine, and can therefore be used in a large source for teletherapy (see above, 'Megavoltage Therapy'). It can be incorporated into needles and tubes for interstitial, intra-cavitary and surface application.

Cæsium 137, a waste product of atomic fission, also emits a gamma-ray equivalent to that produced by a million-volt X-ray machine, and this also is coming into use in teletherapy units for external treatment.

Tantalium 182 can be prepared in the form of a malleable wire. It can be cut to the required length and inserted as an implant to fit any volume of tissue, however irregular it may be. The halflife of ${ }^{182} \mathrm{Ta}$ is only II I days, but a busy centre can easily arrange for a supply to be available constantly. Wallace uses ${ }^{182} \mathrm{Ta}$ in the form of 'hairpins' which are inserted using a special boomerang needle, with the loop end towards the internal urethral orifice. The wires can be removed through the urethra when required, without a further anæsthetic being necessary.

Gold 198 has replaced radon as a short-lived gamma-ray source. Gold grains are implanted in the same way as radon seeds. Preparation of the gold grains does not involve any particular risks and their uniform size allows the use of a 'gun' containing 15 in each magazine. Implantation time and irradiation of the operating theatre staff is greatly reduced (Hodt, Sinclair and Smithers, 1952).

Other isotopes, such as radioiridium, have been investigated as radium and radon substitutes, but none has become generally accepted.

\section{Radioactive Colloids}

The therapeutic use of radioactive colloids depends partly upon their colloidal properties. After intravenous injection the particles are taken up by the reticulo-endothelial system, particularly the liver and spleen. If they are injected interstitially there is local spread and a small quantity is taken up by the normally functioning lymph nodes. In the serous cavities the particles adhere to and largely remain localized to the cavity membranes. By using colloidal preparations of beta-ray emitting isotopes intense local irradiation can be given without the clinical manifestations of whole body irradiation.
Intraperitoneal and intrapleural installation of colloidal preparations of radiogold, chromic phosphate containing ${ }^{32} \mathrm{P}$, and more recently Ytrium 9o, have become established methods of palliating patients with rapidly recurring malignant effusions. This treatment is much less effective if there are large tumour masses present.

The intravenous injection of colloidal ${ }^{198} \mathrm{Au}$ has been recommended by Hahn (1956) in the treatment of chronic leukæmia. If effective chemotherapeutic agents were not available this method of treatment would undoubtedly have become more popular.

The interstitial injection of radioactive colloids has been recommended for carcinoma of the cervix (Allen, Sherman and Camel, 1958) and prostate (Elkins, Flocks and Culp, 1958). Unfortunately, lymph nodes that are extensively invaded by carcinoma will not take up sufficient colloid to ensure destruction of the malignant cells. The method has not become generally popular.

\section{Radiophosphorus}

Phosphorus is utilized in large amounts by the actively growing cell and several attempts have been made to treat malignant disease with ${ }^{32} \mathrm{P}$. Unfortunately, phosphorus is also concentrated in the bone marrow, intestinal epithelium and other actively growing normal tissues. Phosphorus 32 has proved useful only in the treatment of blood malignancies, and although it is effective in many cases of leukæmia, they are probably treated better in the first instance with the chemotherapeutic agents busulphan and chlorambucil. Polycythemia remains the only disease which is probably treated most efficiently with ${ }^{32} \mathrm{P}$. The packed cell volume can be kept below $50 \%$, with intravenous injections of 3 to $5 \mathrm{mc}$., and remissions of two years are not unusual. Recent reports include those by Wiseman (1951), Scott (1953), Harman, Hart and Ledlie (1955) and Fountain (1957). It is possible that acute myeloid leukæmia occurs more frequently as a terminal event with ${ }^{32} \mathrm{P}$-treated patients (Ledlie, I960), but life is prolonged considerably and the frequency of vascular complications is greatly reduced.

\section{Radioiodine and Thyroid Cancer}

Radioiodine has been one of the most exciting and also one of the most disappointing radioisotopes to come into wide clinical use. Iodine is effectively concentrated by some well-differentiated thyroid carcinomas and clearly under these circumstances the patient could be expected to benefit. Unfortunately, it is difficult to destroy all the areas of cancer without repeated doses of 100 to $200 \mathrm{mc}$., and in the past it is quite possible that efforts to increase the uptake of radioiodine 
by making the patient markedly hypothyroid over long periods may have actually increased the rate of growth of the tumour by exciting the pituitary to produce excessive amounts of thyroid-stimulating hormone. About half the well-differentiated alveolar-celled adenocarcinomas will respond to massive doses of 1-thyroxine (Crile, 1957) and it is important to maintain the patient on a sufficient amount to prevent hypothyroidism developing between doses of ${ }^{131} \mathrm{I}$. Most centres can refer to one or two striking successes with radioiodine (Kramer and Concannon, I960), and a large number of patients without sufficient uptake to exert any real therapeutic effect on the course of the disease.

It must not be forgotten that at least a half of the poorly differentiated thyroid cancers, which do not concentrate iodine, respond well to external irradiation. Post-thyroidectomy prophylactic irradiation is justifiable and the response of secondary deposits may be as dramatic as that of deposits of lymphosarcoma.

\section{The Skin}

Skin cancer has been treated successfully by radiotherapy since 1899 . It is unlikely that advances in the last decade will make much difference to the results of treatment. Provided that the patient is seen with an early squamous or basal cell skin cancer, without distant metastases, about $95 \%$ are curable by many different techniquesthe use of superficial X-rays, deep X-rays at a short focal skin distance, radium applicators or a radium or gold grain implant. The cosmetic result after this type of treatment is excellent and the results of radiotherapy compare well with the results of good surgery. Until recently it has been generally thought that operable metastatic glands are treated better by surgery. This concept may change, as it is easier to treat involved glands with modern radiotherapeutic techniques. There is certainly a greater chance of curing patients with inoperable glands with megavoltage therapy than with conventional deep X-rays, when energetic treatment was limited by the skin reaction.

\section{Malignant Lymphoma and Leukæmia}

As a rule these malignant conditions are initially radiosensitive, but the long-term results are disappointing. A belief in their multifocal origin, the confusion that has inevitably followed the difficulties of classification and the use of many names for the same conditions and the increasing interest of the general physician has led to a considerable falling off in the use of radiotherapy in their treatment. In the lymphoma group it is possible to produce long remissions with external radiation, which are far better than any yet reported with chemotherapy alone (Peters and Middlemiss, I958). When the disease is apparently limited to one or a few adjacent lymph node groups, particularly in the upper half of the body, and there are no signs of generalized disease (Stage I and Stage II, Jelliffe and Thompson, 1955), energetic radiotherapy is the treatment of choice. In many generalized cases radiotherapy can produce good remissions (Editorial, Amer. F. Rontgenol., 1960), sometimes when chemotherapy has failed.

Nowadays, most patients with chronic leukæmia are treated initially with chemotherapy. This is not because there are any comparable series showing that chemotherapy produces better results than external irradiation, but because it is a more convenient method. When the disease is resistant to chemotherapy, or when local symptoms are tiresome, local irradiation may be indicated. The natural history of chronic leukæmia, particularly lymphatic, is extremely variable and it is often difficult to assess the long-term value of treatment.

Acute leukæmia often responds dramatically to chemotherapy, but local irradiation has a useful part to play. The author can recall six patients seen in the last three years with local skin, soft tissue or bony infiltrations. These deposits developed during long-term chemotherapy and all responded immediately to small amounts of local radiotherapy.

Recently attempts have been made to treat widespread lymphoma or leukæmia by whole body irradiation or energetic chemotherapy, followed by bone marrow transplantation. One long-term survival of a foreign marrow transplantation has been recorded (Bielby, Cade, Jelliffe, Parkin and Stewart, 1960), but so far the method has been remarkably unsuccessful.

\section{Alimentary System}

Cancer of the lip, tongue and mouth has been treated successfully with radium applicators or implants for many years. The functional and cosmetic results of treatment of the lip are excellent and are superior to those of surgery. Reasonably early tumours arising inside the mouth often respond well to radiotherapy, but radionecrosis of bone has always limited treatment with conventional X-rays. With megavoltage therapy this should be a less frequent complication and the irradiation of tumours adherent to bone may be worth while. Treatment of the posterior third of the tongue, the palate and the oropharynx has been greatly simplified since the introduction of megavoltage therapy (Cade and Lee, I957, Fletcher, MacComb, Chau and Farnsley, r959; Friedman, Southard and Ellett, 1959; MacComb, 1960). 
Esophageal cancer has become more accessible with megavoltage therapy. Many tumours will respond well, but it is not possible to predict their radiosensitivity. It is quite clear that many of these tumours metastasize rapidly, despite a good response at the primary site. Unfortunately, if a cancericidal dose is given to the osophagus, there is a real possibility of the patient developing a stricture which may require dilatation. A possible approach might be the surgical establishment of a short circuit by bringing up a loop of bowel through the anterior mediastinum, followed by radical radiotherapy to the primary tumour, which would not affect the short circuit. Carcinoma of the lower third of the esophagus is always a surgical and not a radiotherapeutic problem.

Cancer of the large bowel and anus may respond remarkably well to high doses of irradiation. Surgical removal is always the treatment of choice, but when the tumour is recurrent or inoperable megavoltage therapy is often worth trying as a palliative measure. Williams (r949) has reported some long-term remissions, using I million-volt X-rays.

\section{Respiratory System}

Cancer of the nasopharynx and paranasal sinuses is rarely treated successfully by surgery alone. The closest co-operation between radiotherapist and surgeon is indicated. In most cases the tumour is first irradiated externally with multiple small fields and the tumour bed is then exposed by a palatal fenestration. This can be closed efficiently with a dental type plate, allowing normal eating and conversation (Windeyer and Wilson, r955; Snelling, 1959).

Cancer of the larynx limited to the vocal cords is a most curable form of tumour. Successful radiotherapy leaves a normal voice and a recurrent tumour can still be successfully excised if the need arises. Megavoltage therapy is unlikely to improve the results, but it will certainly reduce discomfort during and immediately after the treatment (Tudway and Freundlich, 1960).

Bronchial carcinoma can be treated more energetically with megavoltage therapy, but lung fibrosis becomes increasingly severe as the dose is raised above 4,000 rads. It is possible to cure a certain number of tumours with irradiation (Hilton, 1955), but the most satisfactory treatment at the moment is surgery, when the tumour is operable. Unfortunately, a high proportion of patients develop metastases in a few months and the greatest scope for the radiotherapist is with palliation. It is possible to relieve the symptoms of mediastinal compression, dyspnœa, hæmorrhage and pain more regularly and for longer periods than with any form of chemotherapy that has yet been recorded.

Radiation pneumonitis can probably be guarded against with ACTH or cortisone derivatives. Moss (I960) has reported experimental studies indicating the possible benefits of this treatment, but it is very difficult to assess its value in the routine radiotherapy of lung cancer. Morrison and Deeley (1957) suggest that supervoltage X-ray therapy allows treatment to be tolerated better, but that there does not appear to be any marked improvement in the survival rate with this type of treatment.

Hahn has carried out extensive investigations into the use of colloidal radioisotopes, instilled into the affected bronchial segment. The object is to treat both the primary growth and the lymph nodes draining the area. His recent work suggests that silver-coated colloidal gold is absorbed efficiently. Unfortunately, this absorption will be mainly into unaffected lymph nodes (Matuska, Hahn, Carlson, Auerbach and Meneely, 1958).

\section{The Breast}

Breast cancer is becoming increasingly common and the radiotherapist is called upon to treat a large proportion of cases. Recently there has been considerable controversy as to the correct method of treatment in operable cases. The standard radical mastectomy has lost a little' ground and is being supplanted in some centres by either a more radical surgical approach, or by a combination of simple mastectomy and radical radiotherapy. The leading proponent of this technique is McWhirter (1957). The claims made to support this approach are that operable (Stages I and II) cases do at least as well as those treated by radical surgery, and that it is possible to keep at least $30 \%$ of locally advanced cases alive for five years with this treatment, which is better than can be expected with surgery alone. The situation is extremely confused at the present time and until large numbers of patients are treated in controlled series the true position will not be revealed (Smithers, Rigby-Jones, Galton and Payne, 1952).

In the author's experience, it is possible to sterilize histologically not more than $50 \%$ of primary breast tumours and satellite lymph nodes, using external radiotherapy up to a dose of about $4,000 \mathrm{r}$. If this is true, then a radical mastectomy would appear to be the logical treatment in Stages I and early II cases, followed by energetic radiotherapy to the internal mammary chain and supraclavicular nodes. Using megacurie therapy it is possible to give a dose larger than 4,000 r. to the lymph node areas. When the tumour is locally advanced there does not seem to be much place for surgery, except as a rapid method of dealing with 
an unpleasant and odoriferous ulcer. Radical radiotherapy, particularly with megavoltage units, will often succeed in curing the local disease. The controversial cases are those with doubtfully operable axillary lymph nodes. In this group it is possible that axillary dissection may break down tissue barriers and disseminate the disease. X-ray therapy alone may therefore be the best treatment. However, a surgical clearance of the axilla could sometimes cure the patient, and, lastly, the position might be improved with pre-operative radiotherapy followed by a radical dissection. The correct line of treatment in this difficult group is not known and the situation is made more complicated by the recognized disparity between the clinical staging and the microscopical findings when axillary nodes are examined. There is a real need for close co-operation, and not competition, between surgeons and radiotherapists if more knowledge is to be obtained regarding the management of breast cancer. There is no place for the complacent continuance of an 'accepted' technique of, in fact, unproven value in the management of a disease which kills thousands of victims every year.

When there is no hope of cure radiotherapy has a great part to play. There is a danger today of overlooking the value of radiotherapy in the management of advanced breast cancer with the exciting prospects of hormone therapy and chemotherapy that have recently appeared. In spite of the newer methods, X-ray therapy produces the most frequent, rapid and effective local palliation. There is no reason why it should not be combined with hormone therapy. If used in combination with chemotherapy, there will be a greater risk of bone marrow depression than with either method alone.

An interesting method of treating the internal mammary chain recommended recently is the insertion of radioiridium sources through the internal mammary artery.

Radiotherapy is sometimes used to depress the activity of the ovaries or the pituitary. Ovarian function can be depressed and the menopause induced with doses of 400 to 800 r., depending upon the age. However, a larger dose will be required if much effect is to be produced upon the interstitial cells which produce œstrogens. Surgical removal is the surer method and if radiotherapy must be used a dose of $I, 500$ to $2,000 \mathrm{r}$. is probably necessary.

Hypophyseal destruction with external radiation has been unsuccessful, except in the hands of Lawrence and Tobias (1956). They use a finely collimated beam of $190 \mathrm{MV}$. protons, accelerated in the 184 -in. synchro-cyclotron at Berkeley, California. A dose of 24,000 rads is reached in two weeks, without damage to the adjacent structures. Such a method is clearly limited in its general applicability. Forrest, Blair and Valentine (1958). have reported satisfactory results following the insertion of Yttrium-90 pellets into the pituitary fossa via the nasopharynx. Their latest technique screws two parallel sources through the floor of the sella turcica. This prevents rhinorrhoea and fixes the sources in the centre of the gland. Notter (1959) recommends the implantation of a variable large number of ${ }^{90} \mathrm{Y}$ spheres. In his hands $80 \%$ of patients show complete pituitary destruction. Radiation may be combined with surgery by packing the sella turcica, after hypophysectomy, with wax containing Yttrium-9o.

\section{Reproductive System-Female}

Ovarian cancers can sometimes be helped by radiotherapy. On the whole, the response to treatment is disappointing and usually when the tumour is very radiosensitive metastases appear early. Post-operative radiotherapy is worth while, and it is now possible to treat the whole pelvis up to a dose of 5,000 to 6,000 rads over six weeks with megavoltage therapy without excessively distressing side-effects.

Recurrent malignant ascites often accompanies malignant ovarian tumours. This can be relieved in some cases by colloidal radiogold intraperitoneally.

Cancer of the body of the uterus is often low grade and not very radiosensitive. Surgical removal is the treatment of choice, but often the patient is old, obese and diabetic. Under these circumstances good results may follow intracavitary radium or ${ }^{60} \mathrm{Co}$ applicators.

Cervical cancer is probably treated as well by radiotherapy as with a Wertheim's hysterectomy. After radiotherapy a normal vagina may be present, although sometimes the upper third is stenosed. If the cancer does not respond to irradiation, operation can be resorted to. The response can be evaluated by serial sections or by vaginal cytology (Merrill, 1958).

Intracavitary radium followed by orthodox radiotherapy to the pelvic walls has been the mainstay of treatment for nearly 40 years. Cobalt -60 is an excellent, cheap substitute. The only other new approach which may possess advantages is the use of megavoltage therapy for treating the whole pelvis in one block with more advanced cancers (Mellor, 1960). There is more risk when treating a post-operative recurrence. Adhesions may be immobilizing loops of small bowel in the pelvis. They will receive excessive irradiation and stenosis, hæmorrhage and perforation may follow.

In some centres intracavitary radium is followed 
by a Wertheim's hysterectomy. This may lead to some improvement in the survival rates.

\section{Reproductive System-Male}

Testicular tumours are relatively uncommon, but are well worth while treating energetically. The seminoma is extremely radiosensitive and it is worth irradiating not only the para-aortic lymph nodes prophylactically, but also such depressing manifestations as widespread pulmonary metastases. The response may be dramatic. Surgery in the treatment of this tumour is limited to an orchidectomy. Teratomas are less sensitive, but nevertheless irradiation is the treatment of choice. Care must be taken to avoid damaging the kidneys and spinal cord. Rarely it may be worth considering surgical exploration of the retroperitoneal glands.

\section{The Urinary Tract}

The kidney is a common site of cancer. The nephroblastoma of children is extremely radiosensitive, but cure without surgery is unlikely. Radiation is given therefore either as a pre-operative measure to reduce the size of a huge, probably fixed, mass or after removal of the kidney. Scott (1956) reviewed I, I4I cases and concluded that all nephroblastomas can be made operable by radiotherapy.

Renal adenocarcinoma and cancer arising in the renal pelvis and ureter are much less sensitive and a large dose is indicated. Adequate pre- or postoperative treatment is possible now that megavoltage therapy is available.

Bladder cancer is a common form of cancer which illustrates very clearly the growing tendency for close co-operation between surgeon and radiotherapist-with benefit to all concerned. In many centres radiotherapy is considered the treatment of choice, when possible. Small tumours with minimal infiltration are treated by interstitial implantation, preferably of Tantalum-198 ' hairpins' (Wallace, Stapleton and Turner, 1952), or of radiogold grains. Larger infiltrating tumours can be irradiated adequately with megavoltage therapy, often with a rotation technique.

If the disease has spread out into the pelvis, it is doubtful if it is curable with radiotherapy. Bladder cancers are only moderately radiosensitive and the tissues of the whole pelvis will not often tolerate the dose level that is required. If the whole bladder shows generalized mucosal changes, Ellis and Oliver (1955) recommend the introduction of a colloidal solution of ${ }^{198} \mathrm{Au}$, directly into the bladder cavity. The energetic beta-rays penetrate a short distance only and the bladder wall will receive little irradiation. The papillary fronds of each tumour will be heavily irradiated from each side. The method seems promising.

Cancer of the prostate becomes increasingly. common with advancing age. The successes of œstrogens and castration in relieving symptoms and prolonging life have obscured the real value of radiotherapy. Many prostate cancers are radiosensitive. There may be a place for post-operation irradiation when a 'benign ' prostatic enlargement is found to contain cancer on microscopical examination. Treatment is simple with megavoltage therapy, with or without rotation. Excellent palliation can sometimes be obtained when there is no further response to hormone therapy. The intraprostatic injection of colloidal ${ }^{198} \mathrm{Au}$ has been referred to above ('Radioactive Isotopes').

\section{Palliative Radiotherapy}

The widespread use of chemotherapeutic agents in the palliation of cancer has masked the fact that such palliation is variable and of short duration when compared with palliation obtained by local radiotherapy. Bone pains, pressure symptoms, nerve involvement, hæmorrhage, rapidly growing liver deposits and cerebral metastases (Chao, Phillips and Nickson, 1954) may all be relieved. Sometimes the relief may continue for two or more years before other manifestations develop. With a pathological fracture of a long bone it is well worth while internally fixing the fracture and then continuing with radiotherapy (Bremner and Jelliffe, 1958).

\section{The Future}

The treatment of cancer with radiotherapy is a fascinating and rapidly expanding field. The radiotherapist now has adequate apparatus to give any required dose to any part of the body and he is revising his views on the tolerance of the normal tissues. Charged particle irradiation will soon be an accepted part of his armamentarium.

It is possible that worth-while increases in tumour sensitivity may be obtained with chemical substances. This will probably follow a considerable increase in our knowledge of the fundamental radiobiological reactions.

In the field of radioisotopes attempts are being made to encourage tumours to take up compounds emitting either soft gamma- or beta-rays. Mitchell (1959) is working with Synkavit labelled with tritium, which will be given intra-arterially. Other workers are producing antibodies against experimental tumours and tagging the antibodies with isotopes (Bale and Spar, 1957; Pressman, 1957). One of the most ingenious approaches has been the administration of inactive boron to patients with brain tumours. The tumour con- 
centrates the boron, which is then made radioactive by irradiation in a slow neutron beam (Brownell and Sweet, 1958).

Unless an unexpectedly dramatic development occurs in the chemotherapy of cancer, the radiotherapist's part in the management of the cancer patient will become increasingly complex, stimulating and worth while.

\section{REFERENCES}

Allen, M. W., Sherman, A. I., and Camel, H. M. (1958): Radiogold in the Treatment of Cancer of the Cervix, Radiology, 70, 523.

BACQ, Z. M., and AleXANDER, P. (1955): ' Fundamentals of Radiobiology'. London: Butterworth.

BALE, W. F., and SPAR, I. L. (1957): Studies Directed Toward the Use of Antibodies as Carriers of Radioactivity for Therapy, Advanc. biol. med. Phys., 5, 285.

Bane, H. N., Conrad, J. T., and Tarnowski, G. S. (1957): Combination Therapy of Malignant Tumours with Ionizing Radiations and Chemicals: a Review, Cancer Res., 17, 551.

Batchelor, A., Bewley, D. K., Morrison, R., and Stevenson, J. A. (1959): Electron Therapy at 8 MV., Brit. $\mathcal{Y}$. Radiol. N.S., 32, 332.

Bielby, J. O. W., Cade, I. S., Jelliffe, A. M., Parkin, D. M., and Stewart, J. W. (ig60): Prolonged Survival of a Bone-marrow Graft Resulting in a Blood-group Chimera, Brit. med. F., i, 96.

Bremner, R. A., and Jelliffe, A. M. (1958): The Management of Pathological Fracture of the Major Long Bones from Metastatic Cancer, $\mathcal{Y}$. Bone $\mathcal{f} t$ Surg., $40 \mathrm{~B}, 652$.

Brownell, G. L., and SwEET, W. H. (1958): In 'Proceedings of the Second U.N. International Conference on the Peaceful Uses of Atomic Energy, p. 881. Geneva: United Nations.

CAdE, S., and LeE, E. S. (1957): Cancer of the Tongue-a Study Based on 653 Patients, Brit. F. Surg., 44, 433.

ChaO, J., PhILlips, R., and NiCKson, J. J. (1954): Roentgen-ray Therapy of Cerebral Metastases, Cancer, $7,682$.

Churchill-Davidson, I., SANGer, C., and Thomlinson, R. H. (1957): Oxygenation in Radiotherapy: Clinical Application, Brit. F. Radiol. N.S., 30, 406.

Crile, G. (1957): The Endocrine Dependency of Certain Thyroid Cancers and the Danger that Hypothyroidism may Stimulate Their Growth, Cancer, Io, 1119.

Editorial (1960): Radiation Therapy and Adjunctive Chemotherapy in the Treatment of the Lymphomas, Amer. $\mathcal{Y}$. Roentgenol., 84, 775 .

Elkins, H. B., Flocks, R. H., and CulP, D. A. (1958): Evaluation of the Use of Colloidal Radioactive Gold in the Treatment of Prostatic Cancer, Radiology, 70, 386.

Ellis, F., and Oliver, R. (1955): Treatment of Papilloma of Bladder with Radioactive Colloidal Gold Au ${ }^{198}$, Brit. med. Y., i, 136.

EMERY, E. W. (1960): Technique of Irradiation of Conscious Patient Under Increased Oxygen Pressure, Lancet, i, 248.

Flatman, G. E. (1959): Some Observations on the Treatment of Certain Radio-resistant Tumours, F. Fac. Radiol. (Lond.), 10, 21 .

Fletcher, G. H., MacComb, W. S., Chau, P. M., and Farnsley, W. G. (1959): Comparison of Medium Voltage and Supervoltage Roentgen Therapy in the Treatment of Oropharynx Cancers, Amer. Y. Roentgenol., 81, 375.

Forrest, A. P. M., BlaIR, D. W., and VAlentine, J. M. (1958): Screw Implantation of the Pituitary with Ÿttrium-90, Lancet, ii, 192.

Fountain, J. R. (1957): Treatment of Polycythæmia Vera with Radioactive Phosphorus, Brit. med. F., ii, 1335.

Friedman, M., Southard, M. E., and ElLETT, W. (1959): Supervoltage (2 MV.) Rotation Irradiation of Carcinoma of the Head and Neck, Amer. F. Roentgenol., 81, 402.

GALE, N. H., and INNES, G. S. (1960): The Advantages of Employing Mixed High Energy X-ray and Electron Beams in Radiation Therapy, Brit. $\mathcal{Y}$. Radiol., 33, 261.

Gray, L. H., Conger, A. D., EBERT, M., HornSEY, S., and Scott, O. C. A. (1953): The Concentration of Oxygen Dissolved in Tissues at the Time of Irradiation as a Factor in Radiotherapy, Brit. F. Radiol. N.S., 26, 638.

GreEn, A. (1959): A Technical Advance in Irradiation Technique, Proc. roy. Soc. Med., 52, 344.

HAHN, P. F. (1956): in 'Therapeutic Use of Artificial Isotopes' London: Chapman \& Hall.

HARman, J. B., HART, P. L. DE V., and Ledlie, E. M. (1955): Treatment of Polycythæmia with Radioactive Phosphorus, Brit. med. F., i, 930.

HiLton, GwEN (1955): Carcinoma of the Bronchus. In 'British Practice in Radiotherapy', p. 258, ed. Carling, E. R., Windeyer, B. W., and Smithers, D. W. London: Butterworth.

HodT, H. J., SinCLAIR, W. K., and Smithers, D. W. (1952): A Gun for Interstitial Implantation of Radioactive Gold Grains, Brit. Y. Radiol., 25, 419.

Horwitz, H., and HaYBITTLE, J. L. (1960): Whole Body Superficial Irradiation with Strontium 90 Beta-Rays, Ibid., 33, 440.

HumbLe, J. G. (1960): The Application of Sternal Autologous Marrow in the Treatment of Advanced Malignant Disease. Hæmatological Aspects, Ibid., 33, 580 .

JeLLIFFE ${ }_{3}$ A. M. (1961): A Critical Assessment of Supervoltage Rotation Therapy, Ibid., in the press.

, and Thompson, A. D. (1955): The Prognosis in Hodgkin's Disease, Brit. $\mathcal{Y}$. Cancer, 9, 23.

Kramer, S., and ConCANnoN, J. P. (1960): Response of Pulmonary and Soft Tissue Metastases from Carcinoma of the Thyroid to Radioactive Iodine Therapy, Amer. F. Roentgenol., 84, 673.

Kurnick, N. B., Montano, A., Gerdes, J. C., and FEDER, B. H. (1958): Preliminary Observations on the Treatment of Post-irradiation Hæmatopoietic Depression in Man by the Infusion of Stored Autogenous Bone Marrow, Ann. intern. Med., 49, 973 .

LAjTHA, L. G. (1960): Consideration of the Theory of Bone Marrow Grafting as Treatment of Radiation Damage, Brit. F. Radiol., 33, 588.

LAWRENCE, J. H., and TOBIAS, C. A. (1956): Radioactive Isotopes and Nuclear Radiations in the Treatment of Cancer, Cancer Res., 16, 185. 
Ledlie, E. M. (1960): The Incidence of Acute Leukæmia in Patients with Polycythenia, Treated by Radiophosphorus, Clin. Radiol., II, 130.

Lochman, D. J., and MorRIs, R. S. (1956): The Treatment of Lung Cancer with Radiation and Radiomimetic Drugs, Radiology, 66, 842.

MacComb, W. S. (1960): Treatment of Head and Neck Cancer, Amer. F. Roentgenol., 84, 589.

McWhirter, R. (1957): Some Factors Influencing Prognosis in Breast Cancer, F. Fac. Radiol. (Lond.), 8, 220.

Matuska, R. A., Hahn, P. F., Carlson, R. I., Auerbach, S. H., and Meneely, G. R. J. (1958): Further Observations on the Lymphatic Pick-up of Radioactive Silver-coated Gold Colloid Administered Intrathoracically in Dogs, Y. thorac. Surg., 35, 135.

Mellor, H. M. (1960): Carcinoma of the Cervix Uteri: Treatment by Supervoltage Irradiation Only, Brit. F. Radiol., 33, 20.

MerRILL, J. H. (1958): Cytohistological Evaluation of Radiation Response in Carcinoma of the Cervix. In 'Progress in Radiation Therapy', ed. Buske, F. New York and London: Grune \& Stratton.

Mitchell, J. S. (1953): Assessment of Synkavit as a Radiosensitizer in the Radiotherapy of Malignant Tumours, Brit. F. Cancer, $7,313$.

- (1959): Use of Synkavit Labelled with Tritium. At 9th International Radiological Congress, Munich.

(1960): 'Studies in Radiotherapeutics', p. 80. Oxford: Blackwell Scientific Publications.

MoRrison, R., and DeELEY, T. J. (I957): Treatment of Inoperable Cancer of the Bronchus by Megavoltage X-ray Therapy, Lancet, ii, 907.

Moss, W. T., Haddy, F. J., and Sweany, S. K. (1960): Some Factors Altering the Severity of Acute Radiation Pneumonitis: Variation with Cortisone, Heparin and Antibiotics, Radiology, 75, 50.

Newton, K. A. (1960): Total Thoracic Irradiation Combined with Intravenous Injection of Autogenous Bone Marrow, Clin. Radiol., 11, I4.

Nielsen, J., and Jensen, S. H. (I942): Some Experimental and Clinical Lights on the Rotation Therapy, its Basis and Possibility, Acta Radiol. (Stockh.), 23, $5 \mathrm{I}$.

NotTer, G. (1959): A Technique for the Destruction of the Hypophysis Using ${ }^{\circ 0} \mathrm{Y}$ Spheres: A Radiologic, Endocrine and Histologic Study, Ibid., Supplement 184.

PAtT, H. M. (1958): The Modification of Radiation Effects by Chemical Means. In 'Progress in Radiation Therapy'. ed. Buske, F. New York and London: Grune \& Stratton.

Patterson, R. (1960): The Relative Biological Efficiency of 20 MV. and 4 MV. Radiations, Brit. F. Radiol., 33, 27 I.

PEGG, D. E., and KemP, N. H. (1960): Collection, Storage and Administration of Autologous Human Bone Marrow, Lancet, ii, $\mathbf{1 4 2 6 .}$

Peters, M. V., and Middlemiss, K. C. H. (1958): A Study of Hodgkin's Disease Treated by Irradiation, Amer. $\mathcal{F}$. Roentgenol., 79, 114.

PorTer, K. A. (1960): Marrow Transplantation After Radiation: an Experimental Approach to the Immunological Complications, Clin. Radiol., r1, 23.

Pressman, D. (1957): Current Status of the Tissue Localization of Iodine 131-Labelled Antitissue Antibodies, Ann. N.Y. Acad. Sci., 70, 72.

Scotr, L. S. (1956): Wilms's Tumour: Its Treatment and Prognosis, Brit. med. F., i, 200.

SCOTT, R. BODLEY (1953): Treatment of Polycythæmia Rubra Vera, Ibid., i, I 128.

Smithers, D. W., Rigby-Jones, P., Galton, D. A. G., and PAYNe, P. M. (1952): Cancer of the Breast: A Review, Brit. F. Radiol., Supp. No. 4 .

Smithers, D. W. (1954): Rotation Therapy, F. Fac. Radiol. (Lond.), 6, 73.

SNELling, MARGARET D. (1959): Maxillary Antrum and Ethmoids. In' 'Cancer', vol. 5, pp. 145-195, ed. Raven, R. W. London: Butterworth.

Tudway, R. C., and Freundlich, H. F. (1960): $\mathrm{Co}^{60}$ Beam Unit in the Treatment of Laryngeal Carcinoma, Brit. F. Radiol., 33, 98.

Wallace, D. M., Stapleton, J. E., and Turner, R. C. (1952): Radioactive Tantalum Wire Implantation as a Method of Treatment for Early Carcinoma of the Bladder, Brit. F. Radiol. N.S., 25, 421 .

Williams, I. G. (1949): Carcinoma of the Rectum and Anal Canal Treatment with Very High Voltage X-ray Therapy. Brit. F. Surg., 36, 376.

WiNDEYER, B. W., and WiLson, C. P. (1955): Tumours of the Nose and Nasal Sinuses. In 'British Practice in Radiotherapy', p. 208 . London: Butterworth.

Wiseman, B. K., Rohn, R. J., Bouroncle, B. A., and Myers, W. G. (195I): The Treatment of Polycythæmia Vera with Radioactive Phosphorus, Ann. intern. Med., 34, 3 I I. 